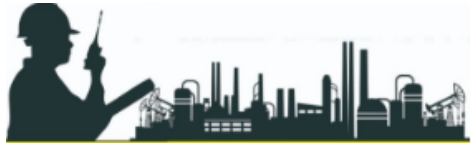

INVANTRI
Jurnal Penelitian

Inovasi Dan Pengelolaan Industri Jurusan Teknik Industri
E-ISSN:

XXX-XXX-XXX

\title{
PERENCANAAN KEBUTUHAN BAHAN BAKU PADA PROSES PRODUKSI TAS DENGAN MENGGUNAKAN METODE MATERIAL REQUIREMENT PLANNING (MRP)
}

Muchammad Bagas Efendi ${ }^{1}$

Teknik Industri, Fakultas Teknik,

Universitas Hasyim Asy'ari

bagasefendi4@gmail.com

Andhika Mayasari ${ }^{2}$ Teknik Industri, Fakultas Teknik, Universitas Hasyim Asy'ari andhikamayasari@gmail.com

Published By: Program Study Teknik Industri Universitas Hasyim Asy'ari Tebuireng Jombang. Email: invantri.unhasy@gmail.com Phone : (0321) 861719

Map \& Adreess : Tebuireng, Jl. Irian Jaya No.55, Cukir, Kec. Diwek, Kabupaten Jombang, Jawa Timur 61471

\section{Abstract}

UD. Elindo Jaya is a home industry engaged in making bags. This home industry manages raw materials into finished goods. Inventory is important for the home industry. Availability of raw materials in the right amount and time is a support for the smooth production process and can avoid shortages and excess of raw materials that can affect costs incurred. The problem that is formulated is how many raw materials for each order and when the components of these raw materials must be available in the warehouse in the right amount and time. The purpose of this study is to determine the amount of raw materials per order so that effectiveness can be achieved and to know the amount and time that must be available for the smooth running of the production process. Material requirement planning (MRP) is a method for knowing the planning of the production process and the raw material requirements for each component and determining the lead time for orders. From the data processing analysis carried out based on the MRP method, the raw material for producing 1000 bags requires 2.2 rolls of varing material on the $3 r d$ day, 2000 sewing threads on the 4th day, 5.5 miniso material on the 3rd day, 2,2 zipper rollers on the 4th day, and $100 \mathrm{M}$ of the rante accessories on the 4 th day.

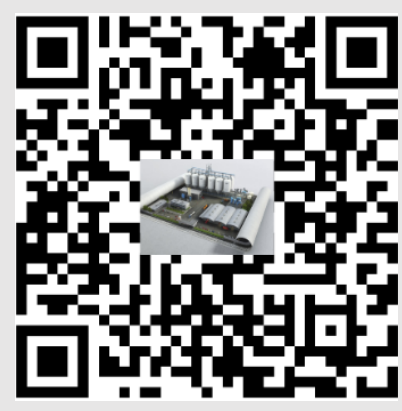

Keywords: raw materials, MRP, method, Inventory, home industry

DOI : $X X X-X X X X-X X X X$

Article History, 


\begin{abstract}
Abstrak
UD. Elindo Jaya merupakan home industry yang bergerak dibidang pembuatan tas. Home industry ini mengelola bahan baku mentah menjadi barang jadi. Persediaan merupakan hal penting bagi home industry. Ketersediaan bahan baku dalam jumlah dan waktu yang tepat adalah penunjang kelancaran proses produksi dan dapat menghindari kekurangan dan kelebihan bahan baku yang dapat mempengaruhi biaya - biaya yang dikeluarkan. Masalah yang dirumuskan yaitu berapa jumlah bahan baku untuk setiap kali pemesanan dan kapan komponen - komponen bahan baku tersebut harus tersedia di Gudang dengan jumlah dan waktu yang tepat. Tujuan penelitian ini adalah untuk mengetahui jumlah bahan baku setiap kali pemesanan agar efektivitas dapat tercapai dan mengetahui jumlah dan waktu yang harus tersedia demi kelancaran proses produksi. Material requirdment planning (MRP) merupakan metode untuk mengetahui perencanaan proses produksi dan kebutuhan bahan baku dalam setiap komponen dan menentukan waktu tunggu pemesanan (Lead Time). Dari analisis pengelolahan data yang dilakukan berdasarkan menggunakan metode MRP adalah bahan baku untuk memproduksi 1000 tas memerlukan 2,2 rol bahan varing pada hari ke - 3, 2000 benang jahit pada hari ke $-4,5,5$ bahan miniso pada hari ke $-3,2,2$ rol resleting pada hari ke -4 , dan $100 \mathrm{M}$ aksesoris rante pada hari ke -4 .
\end{abstract}

Kata Kunci: Bahan Baku, Metode MRP

\section{PENDAHULUAN}

Di era perdagangan bebas sekarang ini, perekonomian mengalami kemajuan yang sangat pesat dan pesaing pelaku sesama ekonimi juga semakin ketat, kemampuan penggunaan dan penyerapan teknologi dalam usaha meningkatkan kinerja home industry harus tetap di tingkatkan agar menghasilkan produk yang berkualitas bagus yang mampu bersaing di pasar. Pengelolahan proses produksi yang baik sangat dibutuhkan agar proses reproduksi berjalan dengan stabil, lancar dan menghasilkan hasil yang optimal. Persediaan merupakan bagian yang sangat penting dalam home industry. jika kekurangan atau keterlambatan persediaan bahan baku tidak bisa di anggap mudah karena bahan baku merupakan bahan pokok/utama dalam proses produksi yang dapat mengakibatkan adanya hambatan proses produksi, sehingga menggangu reproduksi dan dapat menimbulkan kekecewaan pelanggan. Selain itu keseimbangan faktor produksi juga di perlukan untuk menunjang kelancaran aktivitas produksi.

UD. Elindo Jaya adalah salah satu Home Industry tas yang ada di desa Grogolan, kecamatan Mojowarno, kabupaten Jombang dimana produksinya berdasarkan pesanan konsumen. Tentunya Home Industry ini harus mampu menyelesaikan produksinya sesuai waktu yang telah ditentukan. Karena dengan ketepatan produksi yang baik akan menunjang produktivitas Home Industry tersebut, sehingga dapat memaksimalkan laba dan memuaskan konsumen. Masalah yang terjadi di home industri terkait persediaan antara lain jika mendapat order dalam jumlah banyak dengan waktu yang singkat home industri kurang mampu mengelola dengan baik. Masalah tersebut dapat menggangu kelancaran Home Industry.

Metode yang digunakan dalam manajemen persediaan bahan baku salah 
satunya adalah metode Material Requirdment Planning (MRP), metode ini digunakan untuk mengendalikan dan merencanakan persediaan bahan baku yang bergantung pada permintaan yang mejadwalkan jumlah yang tepat dari suatu material yang dibutuhkan untuk mendukung produk akhir yang diinginkan.

Tujuan penelitian ini untuk megetahui jumlah bahan baku pada setiap kali pemesanan agar efektivitas dapat tercapai dan mengetahui kapan bahan baku tersebut harus tersedia dalam jumlah dan waktu yang tepat.

\section{METODE}

Dalam penelitian ini, metode yang digunakan adalah material requirdment planning (MRP) dimana metode ini digunakan untuk merencanakan persediaan bahan baku yang bergantung pada permintaan penjadwalan jumlah yang tepat dari suatu material atau bahan yang dibutuhkan guna mendukung produk akhir yang diinginkan. Metode MRP memiliki empat proses Langkah utama yang terdiri dari, (1) Menyusun Bill Of Material (BOM), (2) Menghitung kebutuhan bersih bahan baku (net requirement), (3) Melakukan lot sizing dan (4) Menyusun time phasing requirement. Proses-proses ini dilakukan berulang hingga semua komponen dibuatkan jadwalnya. Lot size merupakan besarnya pesanan per item yang akan dipesan berdasarkan data kuantitatif pesanan dari item berdasarkan data MRP. LFL (Lot For Lot) merupakan Teknik penetapan ukuran lot yang dilakukan atas dasar pesanan distrik. Teknik ini selalu melakukan perhitungan Kembali (bersifat dinamis) terutama apabila terjadi perubahan kebutuhan bersih. Penulis menggunakan metode MRP ini untuk mengetahui perhitungan bahan baku dalam memproduksi 1000 tas di bulan maret.

\section{HASIL DAN PEMBAHASAN}

Analisis dan Pembahasan Masalah

Dari pengamatan yang sudah di lakukan penulis di UD. Elindo Jaya akan melakukan analisis dan pembahasan mengenai penerapan MRP menggunakan teknik LFL (Lot For Lot) pada perencanaan bahan baku. Rencana pemesanan bahan baku dengan menghitung kebutuhan bahan baku dari order yang di terima dan di peroleh data bahan baku sebagai berikut.

- Benang Jahit

- Bahan croco

- Bahan miniso

- Aksesoris

- Resleting

Input yang digunakan dalam perhitungan bahan baku dan jadwal bahan baku meliputi

- Jadwal induk produksi atau Master Production Schedule (MPS)

- Daftar komponen

- BOM (Bill of material)

- Perencanaan kebutuhan bahan baku dengan MRP.

\section{Pengolahan Data Jadwal Induk Produksi}

Dalam penentuan jadwal induk produksi atau Master Production Schedule (MPS) didasarkan dalam data order produksi yang diterima oleh UD. Elindo Jaya, dengan mempertimbangkan kapasitas produksi atau kemampuan proses home industry, sehingga akan bisa ditentukan berapa jumlah yang akan di produksi dan kapan waktu pelaksanaanya. Pada UD. Elindo Jaya masukan. yang bisa dijadikan dasar untuk menentukan MPS adalah berupa pesananan dari buyer (pembeli) yang diterima. 
Mengenai kapan dan berapa produk yang akan di produksi tentu saja memerlukan pertimbangan kemampuan proses home industry atau setiap bagian processing. Berkaitan dengan produk tas yang akan diangkat dalam penelitian ini, home industry menerima pesanan dari salah satu buyer sebanyak 1000 tas yang semuanya diproduksi 7 hari pada bulan Maret.

\section{Tabel 1 Order Home Industry Bulan Maret}

\begin{tabular}{|l|r|r|r|r|r|r|r|}
\hline Order & \multicolumn{7}{|c|}{ Maret } \\
\hline Hari & 1 & 2 & 3 & 4 & 5 & 6 & 7 \\
\hline Tas Polos & & & 250 & & & & \\
\hline Tas Wiru & & & & 350 & & & \\
\hline Tas Serut & & & & & 400 & & \\
\hline Delivery & & & & & & & 1000 \\
\hline
\end{tabular}

Sumber: Data yang diolah dari UD. Elindo Jaya

Pada tabel 1 menujukkan orderan pada bulan maret selama 7 hari dan 1 buyer memesan 3 model tas di hari yang berbeda dengan jumlah model tas berbeda pula, dan pemesanan 1000 tas akan di produksi di minggu depan.

\section{Pengolahan Daftar Komponen}

Dalam daftar komponen akan tercantumkan berbagai komponen yang digunakan untuk memproduksi suatu produk, dengan jumlahnya masing-masing untuk membuat 1000 tas tersebut. Pada UD. Elindo Jaya dalam menyusun daftar komponen didasarkan pada karakteristik bentuk produk yang diinginkan oleh buyer.

Tabel 2 Daftar komponen per 1 tas

\begin{tabular}{|c|l|c|c|c|}
\hline No & Nama komponen & jumlah & satuan & Lead time \\
\hline 1 & Benang jahit & 2 & biji & 1 \\
\hline 4 & Bahan Varing & 0,0022 & Rol & 2 \\
\hline 5 & Bahan miniso imitasi & 0,0055 & Rol & 2 \\
\hline 6 & Aksesoris rante & 0,1 & Meter & 1 \\
\hline 7 & Resleting & 0,0022 & Rol & 1 \\
\hline
\end{tabular}

Sumber: Data yang diolah dari UD. Elindo Jaya
Pada tabel 2 menunjukkan daftar komponen atau bahan dalam pembuatan 1 model tas.

\section{BOM (Bill Of Material)}

BOM merupakan merupakan sebuah daftar jumlah komponen, campuran bahan, dan bahan baku yang diperlukan untuk membuat suatu produk. (Render \& Heizer, 2001: 358)

Dalam memproduksi 1 tas terdiri dari dua komponen yaitu kantong tas dan tali tas. Kantong dalam 1 tas dibutuhkan 2 biji benang jahit, 0,0022 rol bahan varing 0,0055 rol bahan miniso imitasi dan 0,0022 resleting. Sedangkan untuk tali tas dibutuhkan 2 biji benang jahit, 0,0055 bahan miniso imitasi dan 0,1 meter aksesoris rante. Dibawah ini struktur produk untuk membuat tas.

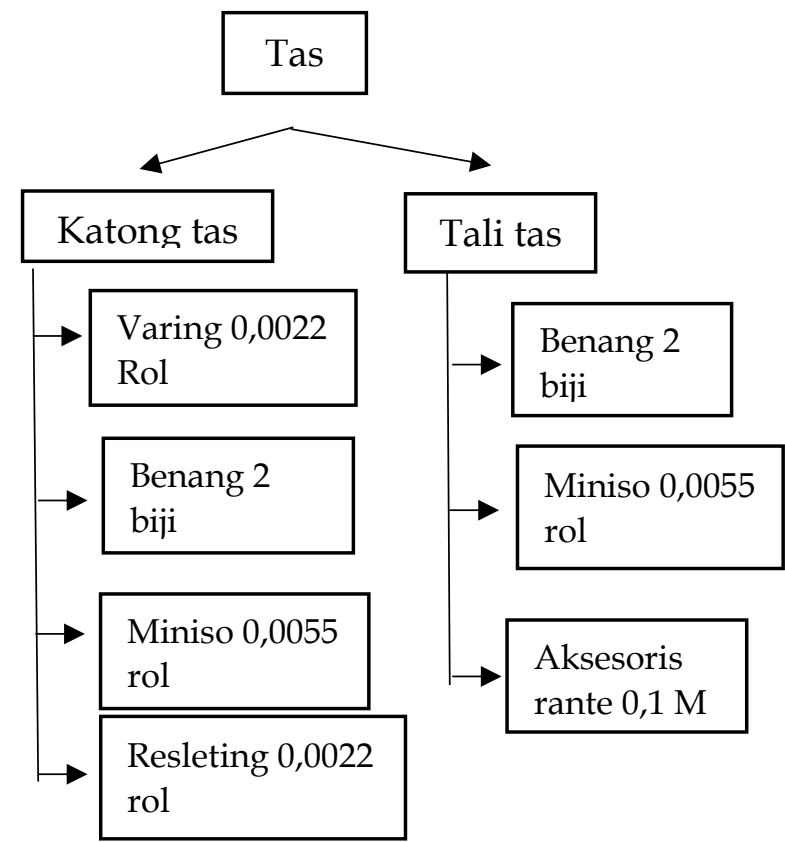

\section{Gambar 1 Struktur produk tas}

Dalam gambar 1 struktur produk di atas, tas (produk utama) menempato level nol, untuk kantong tas dan tali tas menempati level 1 , sedangkan varing, benang, miniso, aksesoris rante menempati level 2 


\section{Rencana Kebutuhan Dengan MRP Untuk Produk Utama Tas}

Tabel 3 MRP Untuk Tas

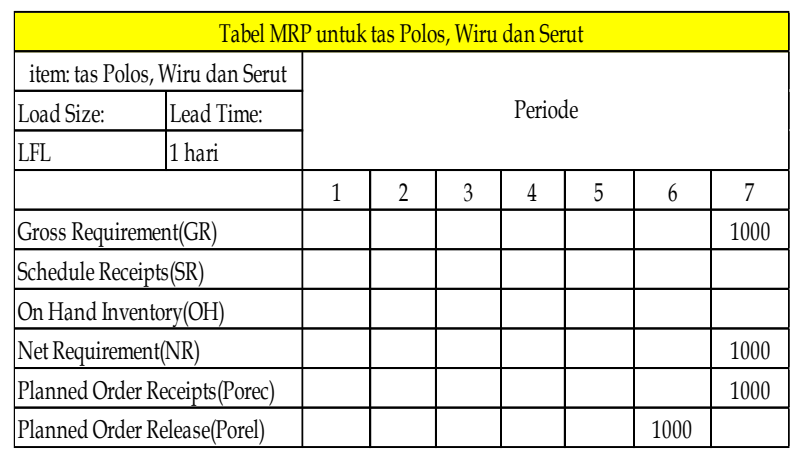

Sumber : Data yang diolah dari UD. Elindo Jaya

Pada tabel 3 memperlihatkan bahwa kebutuhan bruto (Gross Requirement) produk "tas" pada periode 7 sebanyak 1000 tas, seperti yang tercantum dalam MPS. Mengenai rencana pemesanan ( $P . O$ request) mengalami pergeseran 1 hari (periode) dari rencana penerimaannya (P.O receipt). Karena ada lead time yang telah disebutkan diatas maka buku tersebut harus tersedia pada hari ke 6 .

Keterangan :

Total Requirement yaitu keseluruhan jumlah item yang diperlukan pada suatu periode.

On Hand yaitu jumlah persediaan akhir pada suatu periode Schedule Receipt yaitu jumlah item yang akan diterima pada suatu periode tertentu berdasarkan pesanan yang dibuat.

Net Requirement yaitu jumlah kebutuhan bersih suatu item yang diperlukan untuk dapat memenuhi kebutuhan pada periode yang akan datang.

Planned Receipt yaitu jumlah item yang direncanakan untuk diterima.

Planned Request yaitu jumlah item yang akan direncanakan untuk dipesan.

\section{Rencana Kebutuhan Dengan MRP Untuk Kantong Tas}

Tabel 4 MRP untuk kantong tas

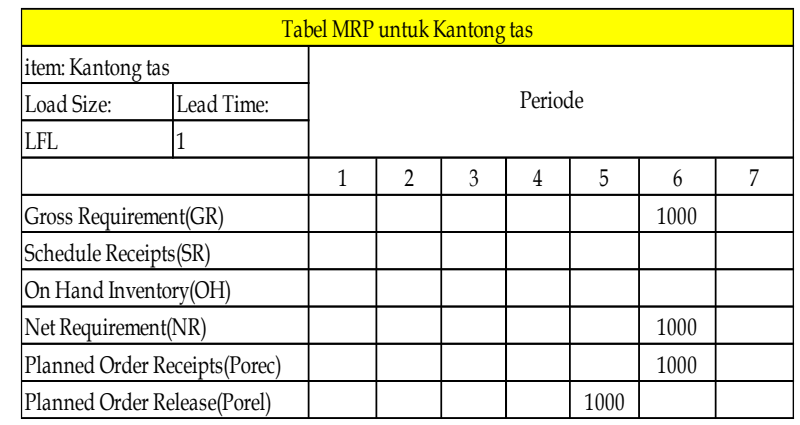

Sumber : Data yang diolah dari UD. Elindo Jaya

Pada tabel 4 memperlihatkan bahwa kebutuhan bruto (Gross Requirement) produk "kantong tas" pada periode 6 sebanyak 1000 tas. Mengenai rencana pemesanan ( $P$.O request) mengalami pergeseran 1 hari (periode) dari rencana penerimaannya ( $P . O$ receipt). Karena ada lead time yang telah disebutkan diatas maka kebutuhan kantong tas tersebut harus tersedia pada hari ke 5 .

\section{Rencana Kebutuhan Dengan MRP Untuk Tali Tas}

Tabel 5 MRP untuk tali tas

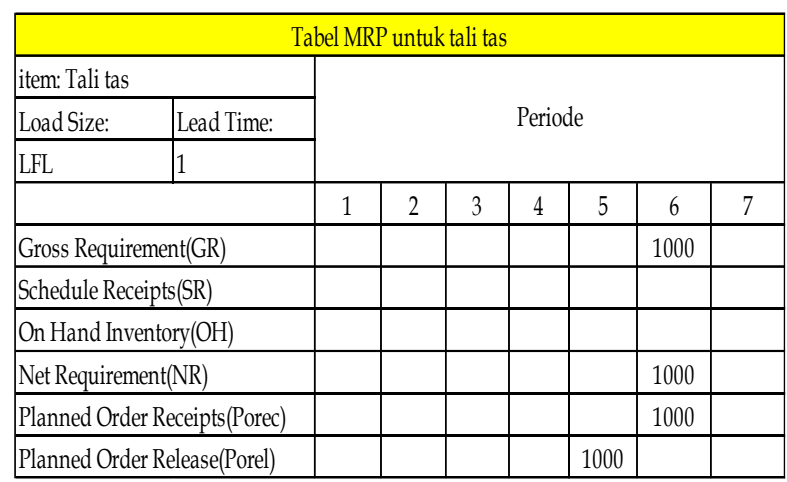

Sumber : Data yang diolah dari UD. Elindo

$$
\text { Jaya }
$$

Pada tabel 5 memperlihatkan bahwa kebutuhan bruto (Gross Requirement) produk "tali tas" pada periode 6 sebanyak 1000 tas. Mengenai rencana pemesanan ( $P . O$ request) mengalami pergeseran 1 hari (periode) dari rencana penerimaannya ( $P . O$ receipt). Karena 
ada lead time yang telah disebutkan diatas maka kebutuhan tali tas tersebut harus tersedia pada hari ke 5 .

\section{Rencana Kebutuhan Dengan MRP Untuk Bahan Varing}

Tabel 6 MRP untuk bahan varing

\begin{tabular}{|c|c|c|c|c|c|c|c|c|}
\hline \multicolumn{9}{|c|}{ Tabel MRP untuk bahan varing } \\
\hline \multicolumn{2}{|c|}{ item: Bahan varing } & \multirow{3}{*}{\multicolumn{7}{|c|}{ Periode }} \\
\hline Load Size: & \multirow{3}{*}{\begin{tabular}{|l} 
Lead Time: \\
2
\end{tabular}} & & & & & & & \\
\hline \multirow[t]{2}{*}{ LFL } & & & & & & & & \\
\hline & & 1 & 2 & 3 & 4 & 5 & 6 & 7 \\
\hline \multicolumn{2}{|c|}{ Gross Requirement(GR) } & & & & & 2,2 & & \\
\hline \multicolumn{9}{|c|}{ Schedule Receipts(SR) } \\
\hline \multicolumn{9}{|c|}{ On Hand Inventory $(\mathrm{OH})$} \\
\hline \multicolumn{2}{|c|}{ Net Requirement(NR) } & & & & & 2,2 & & \\
\hline \multicolumn{2}{|c|}{ Planned Order Receipts(Porec) } & & & & & 2,2 & & \\
\hline \multicolumn{2}{|c|}{ Planned Order Release(Porel) } & & & 2,2 & & & & \\
\hline
\end{tabular}

Sumber : Data yang diolah dari UD. Elindo Jaya

Pada tabel 6 memperlihatkan bahwa kebutuhan bruto (Gross Requirement) produk "bahan varing" pada periode 5 sebanyak 2,2 rol bahan varing. Gross Requirement : 0,0022 rol bahan varing $\times 1000$ tas =2,2 rol bahan varing. Mengenai rencana pemesanan ( $P . O$ request) mengalami pergeseran 2 hari (periode) dari rencana penerimaannya ( $P . O$ receipt). Karena ada lead time yang telah disebutkan diatas maka kebutuhan bahan varing tersebut harus tersedia pada hari ke 3 .

\section{Rencana Kebutuhan Dengan MRP Untuk Benang Jahit}

Tabel 7 MRP untuk benang jahit

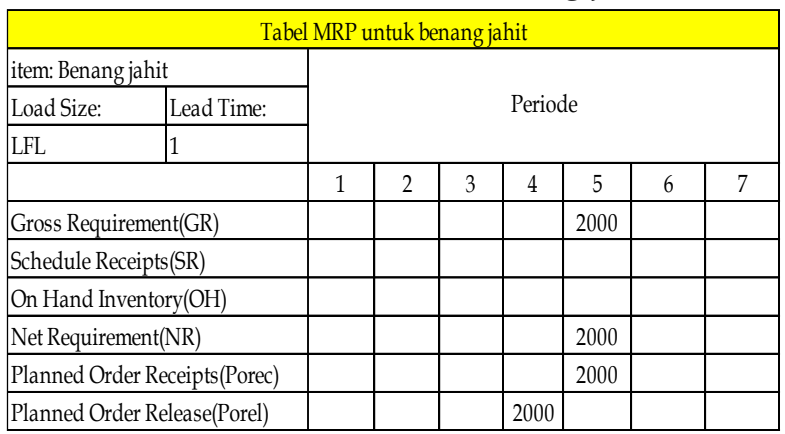

Sumber: Data yang diolah dari UD. Elindo Jaya

Pada tabel 7 memperlihatkan bahwa kebutuhan bruto (Gross Requirement) produk “benang jahit" pada periode 5 sebanyak 2000 benang jaiht. Gross Requirement : 2 biji benang jahit $x 1000$ tas $=2000$ benang jahit. Mengenai rencana pemesanan (P.O request) mengalami pergeseran 1 hari (periode) dari rencana penerimaannya ( $P . O$ receipt). Karena ada lead time yang telah disebutkan diatas maka kebutuhan benang jahit tersebut harus tersedia pada hari ke 4 .

\section{Rencana Kebutuhan Dengan MRP Untuk Resleting}

Tabel 8 MRP untuk resleting

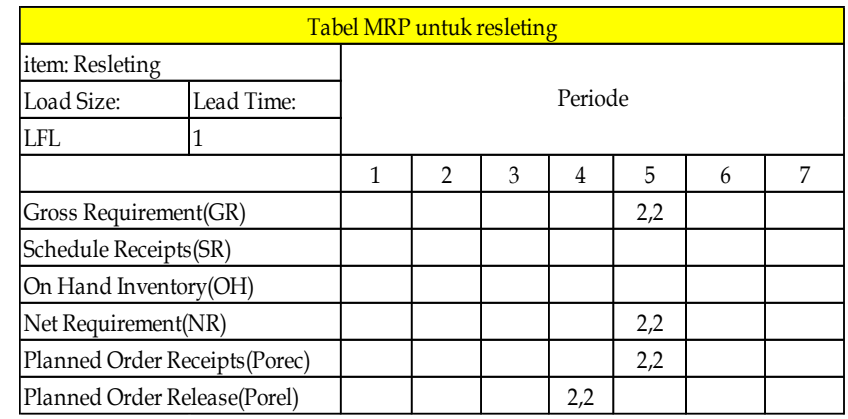

Sumber : Data yang diolah dari UD. Elindo Jaya

Pada Tabel 8 memperlihatkan bahwa kebutuhan bruto (Gross Requirement) produk "resleting" pada periode 5 sebanyak 2,2 rol resleting. Gross Requirement : 0,0022 rol resleting $x 1000$ tas $=2,2$ rol resleting. Mengenai rencana pemesanan (P.O request) mengalami pergeseran 1 hari (periode) dari rencana penerimaannya (P.O receipt). Karena ada lead time yang telah disebutkan diatas maka kebutuhan resleting tersebut harus tersedia pada hari ke 4. 


\section{Rencana Kebutuhan Dengan MRP Untuk Bahan Miniso}

Tabel 9 MRP untuk bahan miniso

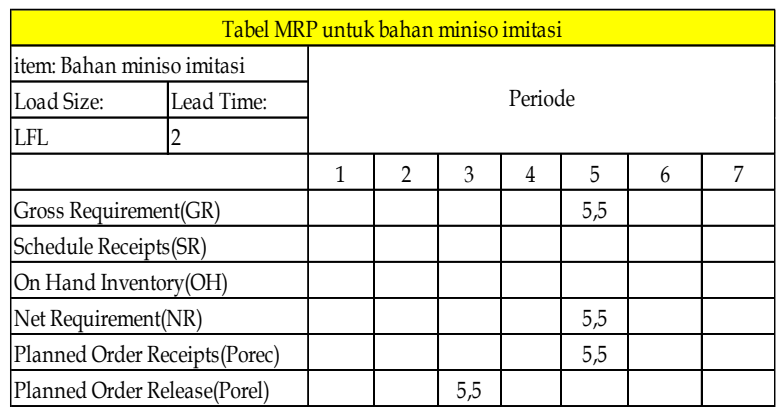

Sumber : Data yang diolah dari UD. Elindo Jaya

Pada tabel 9 memperlihatkan bahwa kebutuhan bruto (Gross Requirement) produk "bahan miniso" pada periode 5 sebanyak 5,5 rol bahan miniso. Gross Requirement : 0,0055 rol bahan miniso $\times 1000$ tas $=5,5 \mathrm{rol}$ bahan miniso. Mengenai rencana pemesanan (P.O request) mengalami pergeseran 2 hari (periode) dari rencana penerimaannya ( $P . O$ receipt). Karena ada lead time yang telah disebutkan diatas maka kebutuhan bahan miniso tersebut harus tersedia pada hari ke 3 .

\section{Rencana Kebutuhan Dengan MRP Untuk Bahan Aksesoris}

Tabel 10 MRP untuk aksesoris rante

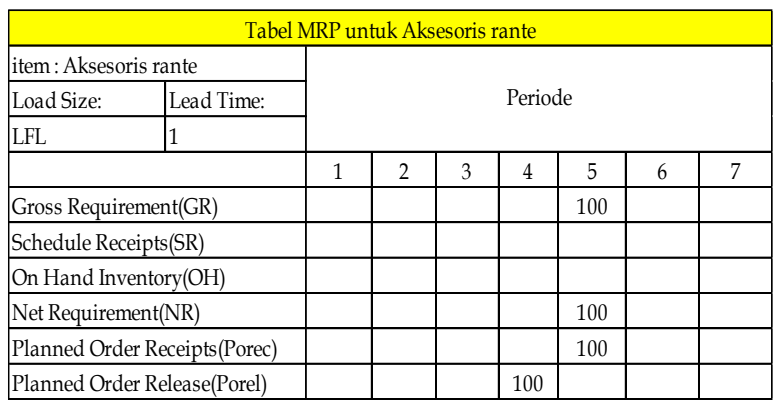

Sumber : Data yang diolah dari UD. Elindo

$$
\text { Jaya }
$$

Pada tabel 10 memperlihatkan bahwa kebutuhan bruto (Gross Requirement) produk "asesoris rante" pada periode 5 sebanyak 100 $\mathrm{m}$ aksesoris rante. Gross Requirement : 0,1 m aksesoris rante $\mathrm{x} 1000$ tas $=100$ benang jahit. Mengenai rencana pemesanan (P.O request) mengalami pergeseran 1 hari (periode) dari rencana penerimaannya (P.O receipt). Karena ada lead time yang telah disebutkan diatas maka kebutuhan aksesoris rante tersebut harus tersedia pada hari ke 4 .

\section{Kebutuhan Kotor Untuk Order Tas}

Dari analisis perhitungan kebutuhan bahan baku dengan metode MRP maka dapat diketahui jumlah kebutuhan kotor (Total Requirement) dan rencana pemesanan (Planned Order Release), dapat dilihat pada tabel berikut

Tabel 11 kebutuhan kotor untuk order tas

\begin{tabular}{|l|c|c|c|c|c|c|c|}
\hline \multirow{2}{*}{ Komponen } & \multicolumn{7}{|c|}{ Periode (dalam hari) } \\
\cline { 2 - 9 } & 1 & 2 & 3 & 4 & 5 & 6 & 7 \\
\hline Kantong tas & & & & & & 1000 & \\
\hline Tali tas & & & & & & 1000 & \\
\hline bahan varing & & & & & 2,2 & & \\
\hline benang jahit & & & & & 2000 & & \\
\hline bahan miniso & & & & & 5,5 & & \\
\hline Resleting & & & & & 2,2 & & \\
\hline aksesoris rante & & & & & 100 & & \\
\hline
\end{tabular}

Sumber : Data yang diolah dari UD. Elindo Jaya

Dari tabel 11 memeperlihatkan kebutuhan kotor pada kantong tas sebanyak 1000 biji dan rencana pemesanan di hari ke - 6 , kebutuhan kotor pada tali tas sebanyak 1000 biji dan rencana pemesanan di hari ke - 6, kebutuhan kotor pada bahan varing sebanyak 2,2 rol dan rencana pemesanan di hari ke - 5, kebutuhan kotor pada benang jahit sebanyak 2000 dan rencana pemesanan di hari ke - 5, kebutuhan kotor pada bahan miniso sebanyak 5,5 rol dan rencana pemesanan di hari ke - 5, kebutuhan kotor pada resleting sebanyak 2,2 rol dan rencana pemesanan di hari ke - 5, kebutuhan kotor pada aksesoris rante sebanyak 100 meter dan rencana pemesanan di hari ke - 5 .

\section{Pemesanan Material Pembuatan Tas}

Rencana pemesanan material (Planned Order Release) tas pada bulan Maret 2021 dapat dilihat pada tabel dibawah ini : 
Tabel 12 pemesanan material pembuatan tas

\begin{tabular}{|l|c|c|c|c|c|c|c|}
\hline \multirow{2}{*}{ Komponen } & \multicolumn{7}{|c|}{ Periode (dalam hari) } \\
\cline { 2 - 8 } & 1 & 2 & 3 & 4 & 5 & 6 & 7 \\
\hline Kantong tas & & & & & 1000 & & \\
\hline Tali tas & & & & & 1000 & & \\
\hline bahan varing & & & 2,2 & & & & \\
\hline benang jahit & & & & 2000 & & & \\
\hline bahan miniso & & & 5,5 & & & & \\
\hline Resleting & & & & 2,2 & & & \\
\hline aksesoris rante & & & & 100 & & & \\
\hline
\end{tabular}

Sumber: Data yang diolah dari UD. Elindo Jaya

Dari tabel 12 memeperlihatkan kebutuhan material pembuatan tas mulai dari kantong tas membutuhkan 1000 biji di hari ke - 5, tali tas membutuhkan 1000 biji di hari ke 5, bahan varing membutuhkan 2,2 rol di hari ke -3 , benang jahit membutuhkan 2000 biji di hari ke - 4, bahan miniso membutuhkan 5,5 rol di hari ke -3, resleting membutuhkan 2,2 rol di hari ke - 4, aksesoris rante membutuhkan 100 meter di hari ke - 4 .

\section{PENUTUP}

\section{Kesimpulan}

Berdasarkan hasil analisis dengan menggunakan metode Material Requirement Planning (MRP) yang telah dilakukan terhadap data yang diperoleh dari UD. Elindo jaya ada beberapa kesimpulan yang dapat diambil dalam tugas akhir ini diantaranya :

1. Dari hasil analisis perhitungan kebutuhan bahan baku dengan metode MRP, maka dapat diketahui :

a. Bahan baku untuk memproduksi 1000 tas memerlukan 2,2 rol bahan varing pada hari ke-3, 2000 benang jahit pada hari ke-4, 5,5 bahan miniso pada hari ke3, 2,2 rol resleting pada hari ke-4, $100 \mathrm{~m}$ aksesoris pada hari ke-4.

b. Rencana pemesanan (Planned Order Release) bahan baku tas yang digunakan untuk proses produksi meliputi : bahan varing, bahan miniso imitasi, benang jahit, resleting dan aksesoris rante
2. UD. Elindo Jaya masih menggunakan perkiraan sebagai pedoman untuk menentukan kapan dan berapa banyak bahan baku yang dibutuhkan dalam proses produksi. Home industri membeli bahan baku dengan mempertimbangkan orderan. Rencana pemesanan bahan baku dilakukan dengan menghitung kebutuhan bahan baku dari order yang di terima. Perencanaan tersebut kurang baik karena dapat mengakibatkan keterlambatan pengiriman barang.

3. Dengan perencanaan menggunakan metode Material Requirement Planning (MRP) Home industri dapat mengendalikan waktu pengiriman bahan baku yang lebih baik, yang memastikan bahwa material dapat tiba kira-kira pada saat tepat ketika material itu dibutuhkan dalam proses produksi. Selain itu dengan menggunakan metode MRP biaya persediaan berkurang, karena dengan metode MRP dapat mengendalikan persediaaan bahan baku sehingga tidak terjadi kelebihan persediaan dan keterlambatan pengiriman barang.

\section{Saran}

Berdasarkan hasil analisis dengan menggunakan metode Material Requirement Planning (MRP) yang telah dilakukan terhadap data yang diperoleh dari UD. Elindo Jaya ada beberapa saran yang dapat diambil dalam tugas akhir ini yaitu:

Home industri perlu menerapkan sistem Material Requirement Planning (MRP) dalam jangka panjang untuk perencanaan kebutuhan bahan baku. Karena dalam hali ini metode Material Requirement Planning dapat membantu perencanaan kebutuhan bahan baku setiap item produk secara tepat waktu dan tepat jumlah. sehingga proses produksi akan terlaksana dengan baik sesuai kapasitas yang direncanakan dan order dapat terpenuhi tepat waktu. 


\section{DAFTAR PUSTAKA}

Arman Hakim \& Yudha Prasetyawan. 2008. Perencanaan \& Pengendalilan Produksi. Yogyakarta Graha Ilmu.

Anaa Anisa. 2011. Perencanaan Kebutuhan Bahan Baku Pada Proses Produksi Karung Plastik Dengan Menggunakan Metode MRP. Surakarta,

Iswandi Idris. 2015. Analisis Perencanaan Kebutuhan Bahan Baku Dengan Menggunakan MRP. Teknik Industri, Politeknik LP3I Medan.

Ginting, Rosnani. 2007. Sistem Produksi. Yogyakarta: Graha Ilmu.

Gitosudarmo, Indriyo dan Agus Mulyono. 2002. Manajemen Bisnis Logistik. Yogyakarta : BPFE

Purnomo, Hari. 2004. Pengantar Teknik Industri. Edisi Kedua. Yogyakarta : Graha Ilmu. 